23

\title{
Особенности регистрации спектра ядерного магнитного резонанса конденсированной среды при экспресс-контроле ее состояния
}

\author{
(C) В.В. Давыдов ${ }^{1}$, А.В. Мороз ${ }^{1}$, Н.С. Мязин ${ }^{1}$, С.С. Макеев ${ }^{1}$, В.И. Дудкин ${ }^{2}$ \\ ${ }^{1}$ Санкт-Петербургский политехнический университет Петра Великого, \\ 195251 Санкт-Петербург, Россия \\ ${ }^{2}$ Санкт-Петербургский государственный университет телекоммуникаций им. проф. М.А. Бонч-Бруевича, \\ 193232 Санкт-Петербург, Россия \\ e-mail: Davydov_vadim66@mail.ru
}

Поступила в Редакцию 16.02.2020 г.

В окончательной редакции 19.02.2020 г.

Принята к публикации 03.07.2020 г.

Обоснована необходимость регистрации спектра ядерного магнитного резонанса (ЯМР) в слабом поле от конденсированной среды при экспресс-контроле ее состояния. Установлены условия, которые позволяют реализовать регистрацию спектров ЯМР в слабом поле. Разработана новая конструкция малогабаритного ядерно-магнитного спектрометра для регистрации спектра ЯМР в слабом магнитном поле от объема конденсированной среды порядка $3.0 \mathrm{ml}$. Представлены результаты экспериментальных исследований различных сред.

Ключевые слова: малогабаритный спектрометр, ядерный магнитный резонанс.

DOI: $10.21883 /$ OS.2020.10.50031.102-20

\section{Введение}

В настоящее время одной из актуальных задач прикладной физики является разработка быстрых и надежных методов экспресс-контроля состояния конденсированных сред [1-4]. Исследования различных сред в экспресс-режиме наиболее востребованы для контроля их состояния перед проведением различных физических и химических экспериментов (особенно после длительного хранения среды, перемены емкости или транспортировки), во время экологического мониторинга труднодоступных мест водных объектов и их прибрежных зон, а также в случаях контроля качества продукции и т. д. $[4-8]$.

Для проведения исследований конденсированных сред в экспресс-режиме разработано большое количество приборов с использованием различных физических явлений [1-8]. Но большинство из них могут применяться только для контроля состояния небольшого числа конденсированных сред или предназначены для решения достаточно узкого круга задач. Например, экспрессанализатор „ИТ-1“ для определения процентного содержания воды в моторном, трансформаторном масле и дизельном топливе или анализатор LactoStar для экспрессанализа качества молочных продуктов. Поэтому наибольшее применение с точки зрения функциональных возможностей в экспресс-контроле получили оптические приборы: спектрофотометры, фотометры, фотоколориметры и т.д. $[9,10]$. Например, экспресс-спектрофотометр ЮНИКО 1200 (1201) (работает в спектральном интервале 325-1000 nm, позволяет определять содержание и концентрацию в растворах достаточно боль- шого числа элементов, вес $8.5 \mathrm{~kg}$, потребляемая мощность $P_{n}=200 \mathrm{~W}$ ) или оптический экспресс-анализатор SPRINT для определения содержания белка и азота в различных веществах (длина волны $480 \mathrm{~nm}$, вес $12.6 \mathrm{~kg}$, $P_{n}$ более $\left.300 \mathrm{~W}\right)$. Массо-габаритные и энергетические характеристики приборов такого типа позволяют их успешно эксплуатировать только в условиях стационарной или мобильной лаборатории. Перенос их на значительные расстояния, а также использование в полевых условиях (питание от аккумуляторов) создают большие сложности как в эксплуатации, так и в проведении измерений. Портативные фотометры (весом менее $4 \mathrm{~kg}$ ) и флуориметрические индикаторы в большинстве случаев предназначены для экспресс-исследования в полевых условиях состояния определенной среды илио бладают ограничениями в использовании. Например, портативный фотометр pHotoFlex (для определения состояния воды и рН), портативный спектрофотометр DR 190 видимого диапазона (фирмы HACH-LANGE) для контроля состояния жидких сред с мутностью не более $10 \mathrm{FNU}$ (при более высоких FNU погрешность измерения увеличивается до $10 \%$ и выше) или флуориметрический индикатор нефтепродуктов „СОЛАР“ ИНПФ-01 ЭП. Использование их в качестве универсального прибора для надежного экспресс-контроля состояния различных конденсированных сред (жидких, гелеобразных, малопрозрачных, порошков и т.д.) невозможно.

В последнее время по различным причинам к методам экспресс-контроля стали предъявлять повышенные требования, среди которых кроме высокой точности измерения (погрешность не выше $1.5 \%$ ) и универсальности используемого метода (применим для исследо- 
вания большого числа сред) появилось еще одно. Оно в большинстве случаев стало первостепенным. Проведенное исследование при экспресс-контроле не должно изменять химический состав и физическую структуру исследуемой среды [1-6,8-10]. Это необходимо для получения подтверждения выявленного отклонения в данной пробе конденсированной среды (особенно это актуально в таможенном контроле или при проверке качества продукции) при ее исследовании в спектрометрах высокого разрешения (например, многофункциональные рентгеновские, оптические или магнито-резонансные). Результаты исследования среды в таких приборах дают исчерпывающую информацию о ее составе. Но данные приборы располагаются только в стационарных лабораториях (на значительном удалении от места проведения эксперсс-контроля). Они являются дорогостоящим оборудованием, которое требует специальных условий эксплуатации и значительных материальных затрат на обслуживание [4-9,11-13]. Поэтому загружать их желательно только образцами, в которых выявлено отклонение от стандартного состояния с целью подтверждения результатов экспресс-контроля.

Такие высокие требования наложили значительные ограничения на использование большинства применяемых в экспресс-контроле методов. Например, при использовании экспресс-спектрофотометров для исследования жидких сред с повышенной мутностью необходимо увеличить мощность лазерного излучения $[1,9,13,14]$. Это может привести к повышению температуры в среде, что будет сопровождаться структурными изменениями (в некоторых случаях необратимыми), в биологических растворах могут погибнуть живые организмы и т.д.

Использование для экспресс-контроля явления ядерного магнитного резонанса (ЯМР) является одним из возможных вариантов решения данной задачи, так как исследования, проводимые методом ядерно-магнитной спектроскопии, не вносят необратимых изменений в физическую структуру и химический состав исследуемой среды. Но как показали проведенные нами исследования, малогабаритные ЯМР-измерители, рассмотренные в [5-8] для определения состояния среды по измеренным константам релаксации $T_{1}$ и $T_{2}$, имеют ряд ограничений в работе, которые в первую очередь связаны с регистрацией сигнала ЯМР от малого объема исследуемой среды $\left(V_{R}<0.3 \mathrm{ml}\right)$ в слабом магнитном поле $\left(B_{0}<0.1 \mathrm{~T}\right)$. Основное ограничение - это невозможность использования системы автоматической подстройки частоты (АПЧ) $f_{\text {nmr }}$ на резонанс из-за низкого отношения сигнал/шум $(S / N \leq 1.3[15])$ регистрируемого сигнала ЯМР от различных ядер, кроме протонов. Поэтому, чтобы сохранить достаточно широкий диапазон применения, разработанный ранее малогабаритный ЯМР-релаксометр $[4,6,8]$ был настроен на частоту регистрации сигналов ЯМР от протонов $f_{\mathrm{p}}$ (что соответствует гиромагнитному соотношению $\gamma=42.57637513 \mathrm{MHz} / \mathrm{T})$. Это являлось единственным эффективным решением, так как более $85 \%$ жидких сред содержат в своем составе протоны, которые обладают наибольшей чувствительностью к методу ЯМР по сравнению с другими ядрами, имеющими магнитный момент $[8,12,16,17]$. Для компенсации низкого отношения $S / N$ в нем при проведении измерений $T_{1}$ и $T_{2}$ использовалась схема накопления сигнала ЯМР.

В последние годы в различных областях науки и техники используется достаточно большое количество конденсированных сред (например, $\mathrm{NaF}, \mathrm{FeCl}_{3}, \mathrm{MnS}$ и т.д.), в которых не содержатся протоны, но в них есть ядра, обладающие магнитным моментом: $\mathrm{Na}, \mathrm{F}$, $\mathrm{Fe}, \mathrm{Cl}, \mathrm{Mn}, \mathrm{S}$ и т.д. Эти среды в различных случаях перед использованием также необходимо исследовать в экспресс-режиме.

Для таких сред нами было установлено, что в случае перестройки частоты $f_{\text {nmr }}$ в ранее разработанном малогабаритном ЯМР-релаксометре $[4,6,8]$ с резонанса протонов $f_{\mathrm{p}}$ (если его первоначально настроили на эту частоту регистрации сигналов ЯМР), например, на резонансную частоту $f_{\mathrm{Cl}}$ ядер хлора работа системы АПЧ может быть затруднена. Это связано с тем, что отношение $S / N$ на $f_{\mathrm{Cl}}$ меньше 1.3.

Проведенные эксперименты показали, что использование схемы накопления сигнала ЯМР при АПЧ на резонанс в случае перестройки частоты регистрации $f_{\text {nmr }}$ с одних ядер на другие при $S / N<1.3$ нецелесообразно, так как в этом случае время $t_{R}$ измерения констант релаксации $T_{1}$ и $T_{2}$, по которым определяется состояние среды $[1,4,6,8,17]$, увеличивается до $20 \mathrm{~min}$ и более. При таких временах эффективность определения состояния исследуемой среды ЯМР-релаксометром в экспресс-режиме значительно снижается. Кроме того, при использовании ЯМР-релаксометра в полевых условиях $[4,6,8]$ за такой промежуток времени $\left(t_{R} \geq 1200 \mathrm{~s}\right)$ возможны изменения окружающей среды (например, температуры и т.д.), которые могут привести к увеличению погрешности измерения констант релаксации $T_{1}$ и $T_{2}$ до $10 \%$. В случае таможенного экспресс-контроля подобные времена измерения $t_{R}$ недопустимы $[4,6,9]$.

Для получения достоверных результатов $[5,6,9,14]$ в некоторых случаях перед их использованием (как для проведения исследований, так и для других целей) кроме состояния конденсированной среды необходимо определить концентрацию в ней компонент, из которых она состоит (например, $\mathrm{HCl}, \mathrm{NaF}, \mathrm{NaOH}$ или $\mathrm{FeCl}_{3}$ ), кислотность $(\mathrm{pH})$ и т. д. Как показали эксперименты, это особенно важно, если среда используется после длительного хранения, перемены емкости и т. д. $[6,8,9,13,14]$. Рассмотренные ранее портативные фотометры позволяют определять только рН жидких сред в экспресс-режиме.

Для решения этих задач в экспресс-режиме с использованием метода ядерно-магнитной спектроскопии были разработаны и собраны: новая малогабаритная магнитная система, схемы регистрации сигнала ЯМР, обработки и управления. Их использование привело к появлению ряда особенностей, возникающих как при регистрации сигнала ЯМР, так и при проведении самих 
измерений, в отличие от тех, которые были ранее рассмотрены в $[4,6,8]$.

Поэтому целью работы является уточнение наиболее важных из них и учет их в конструкции малогабаритного ЯМР-спектрометра для увеличения его функциональных возможностей - в первую очередь по регистрации спектральных линий на резонансных частотах ядер элементов, входящих в состав конденсированной среды.

\section{Конструкция ЯМР-спектрометра и особенности регистрации сигналов ЯМР}

Проведенные авторами исследования показали, что чтобы сохранить мобильность малогабаритного ЯМР-спектрометра, вес магнитной системы прибора не должен превышать $4 \mathrm{~kg} \quad[1,4,6,8]$. Кроме того, для определения констант релаксации (времен продольной $T_{1}$ и поперечной $T_{2}$ релаксации) с погрешностью не выше $1.0 \%$ неоднородность магнитного поля в катушке регистрации сигнала ЯМР должна быть не хуже $10^{-3} \mathrm{~cm}^{-1}[1,4,6,8,17]$.

На рис. 1 представлена структурная схема малогабаритного ЯМР-спектрометра с разработанными нами новыми элементами конструкции. Малогабаритная магнитная системы была изготовлена с использованием магнитов из материала $(\mathrm{Nd}-\mathrm{Fe}-\mathrm{B})$ в форме диска 1 c большой остаточной индукцией. В ней при диаметpe полюсов магнита $d_{\mathrm{M}}=92 \mathrm{~mm}$ и расстоянии между ними $d_{z}=16 \mathrm{~mm}$ была обеспечена неоднородность $0.5 \cdot 10^{-3} \mathrm{~cm}^{-1}$ при индукции $B_{0}=0.102 \mathrm{~T}$. Вес магнитной системы с катушками модуляции 5 и регистрации 6 , с фиксирующим устройством контейнера 7 составил $3.21 \mathrm{~kg}$. На рис. 2 в качестве примера представлены зарегистрированные сигналы ЯМР от соляной кислоты $\mathrm{HCl}$ по ядрам хлора. В ранее разработанной конструкции малогабаритного ЯМР-релаксометра $[4,6,8]$ исследование соляной кислоты было возможно только с использованием сигнала ЯМР, регистрируемого на резонансной частоте $f_{\mathrm{p}}$ протонов. Анализ представленных на рис. 2 сигналов ЯМР показывает, что при их регистрации на резонансной частоте ядер хлора $f_{\mathrm{Cl}}$ отношение $S / N>1.3$. Это позволяет осуществлять АПЧ $f_{\mathrm{nmr}}$ на резонанс по ядрам хлора. Но без использования схемы накопления для измерения констант релаксации $T_{1}$ и $T_{2} \mathrm{c}$ погрешностью не выше $1.0 \%$, позволяющее однозначно определять состояния среды $[1-4,6,8]$, пока не обойтись, так как отношение $S / N<3.0$ (рис. 2,a). Кроме того, на пиках сигнала ЯМР присутствуют шумы. Последующее накопление сигнала ЯМР позволяет получить отношение $S / N>10.0$ (рис. $2, b$ ), обеспечивающее измерение $T_{1}$ и $T_{2}$ с необходимой точностью.

Полученные экспериментальные результаты показывают, что только за счет улучшения параметров магнитной системы спектрометра не удается добиться регистрации сигналов ЯМР с $S / N$ не ниже 1.3 от ядер с низкой чувствительности к методу ЯМР в слабых магнитных полях. Для решения этой задачи необходим поиск новых решений и методик. Стандартные увеличение $B_{0}$ или объема катушки регистрации $V_{R}$ в малогабаритных ЯМР-измерителях — исчерпали все свои возможности. Это связано с тем, что для регистрации сигналов в малогабаритном ЯМР-спектрометре в слабых магнитных полях используется модуляционная методика $[1,4,6,8,15]$. В этом случае между полюсами магнитов кроме контейнера с исследуемой средой и катушкой регистрации 6 размещаются катушки модуляции 5, занимающие часть объема межполюсного пространства. Поэтому, например, стандартное увеличение значения $B_{0}$ для повышения $S / N$ за счет уменьшения расстояния между полюсами магнитов в данной конструкции спектрометра возможно только за счет уменьшения габаритов катушек модуляции - использование бескорпусных катушек. В случае увеличения $V_{R}$ также придется уменьшать размеры катушек модуляции 5 .

Но проведенные экспериментальные исследования показали, что для регистрации сигнала ЯМР в слабом магнитном поле с использованием модуляционной методики должно выполняться следующее соотношение:

$$
\gamma H_{m}>10 f_{\mathrm{nmr}},
$$

где $H_{m}$ - амплитуда поля модуляции, $\Delta f_{\mathrm{nmr}}-$ естественная ширина линии сигнала ЯМР.

В слабых магнитных полях с высокой степенью однородности величина $\Delta f_{\mathrm{nmr}}$ определяется следующим соотношением [16,17]:

$$
\Delta f_{\mathrm{nmr}}=1 / T_{2} .
$$

Полученное соотношение (1) накладывает ряд ограничений как на размеры и конфигурацию катушек модуляции 5 , так и на значение $H_{m}$, что является одной из особенностей регистрации сигналов ЯМР в слабых полях. Данная особенность в случае миниатюризации катушек модуляции создаст большие сложности с получением в них необходимой величины $H_{m}$, когда малогабаритным ЯМР-спектрометром будут исследоваться среды с $T_{2}<1 \mathrm{~ms}$.

Поэтому авторы в новой разработанной магнитной системе предложили следующее решение: был увеличен $V_{R}$ и уменьшена величина $\Delta B$. При этом был достигнут оптимум между значениями $B_{0}, \Delta B$ и $V_{R}$, позволяющий получать $S / N>1.3$ регистрируемого сигнала от различных ядер исследуемых сред с низкой чувствительностью к методу ЯМР, а также числом пиков („виглей“) в сигнале ЯМР не менее 5 (рис. 2, b), которое позволяет проводить измерения $T_{2}$ с погрешностью не выше $1.0 \%[1,4,6,8,17]$.

Уменьшение степени неоднородности магнитного поля удалось достичь размещением на полюсах магнитов вставок 2 (рис. 1) в виде ступенек (шиммов) из мягкого магнитного материала (Армко-железа). Разработанные нами вставки представляют собой диски с диаметром 


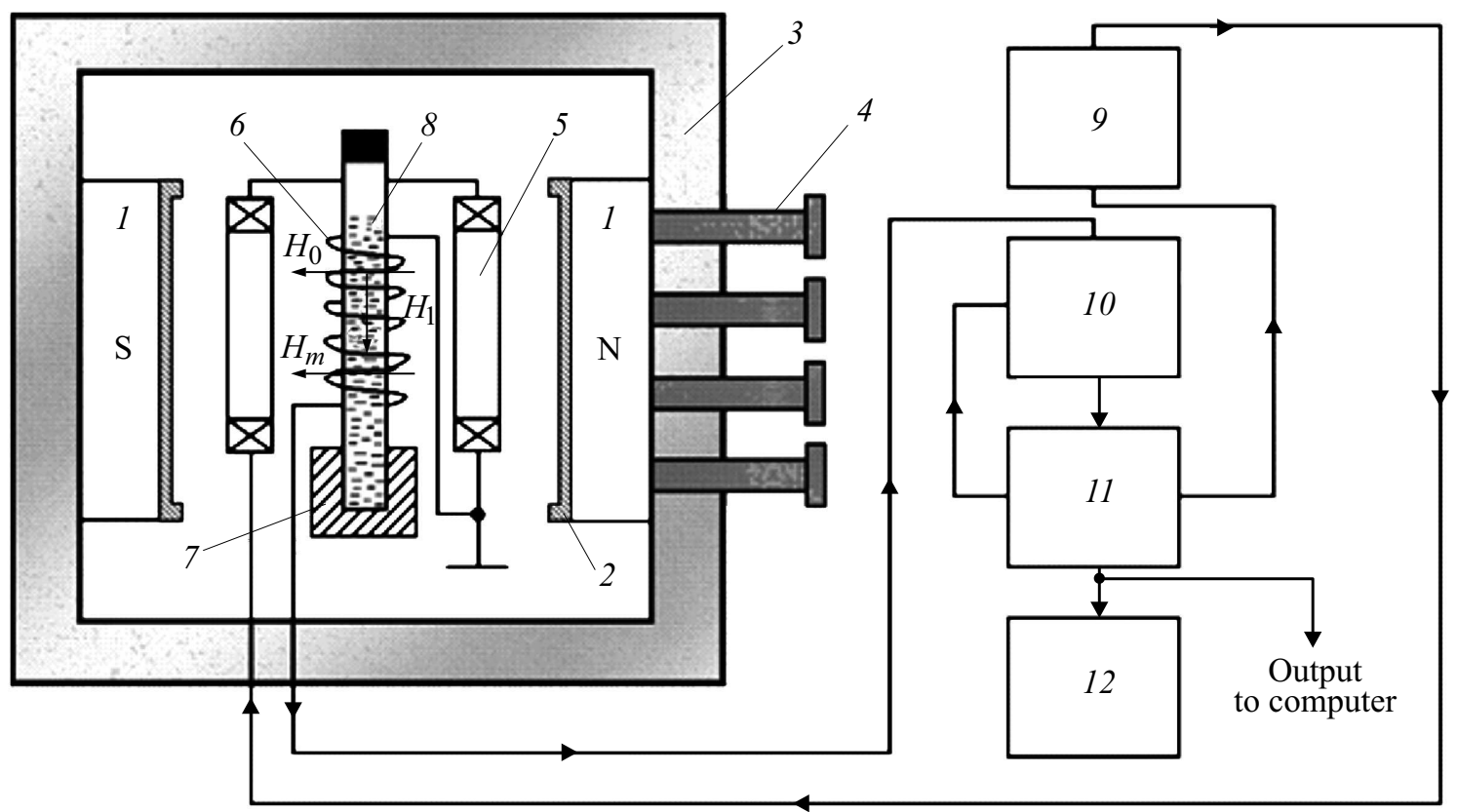

Рис. 1. Структурная схема малогабаритного ЯМР-спектрометра: 1 - постоянный магнит; 2 - вставки (шиммы); 3 - нейтраль для размещения и центровки магнитов; 4 - регулировочные винты; 5 - катушки модуляции; 6 - катушка регистрации сигнала ЯМР; 7 - фиксирующее устройство для контейнера с исследуемой средой; 8 - контейнер с исследуемой средой; $9-$ генератор низкой частоты; 10 - автодинный детектор; 11 - устройство обработки и управления; 12 - осциллограф.
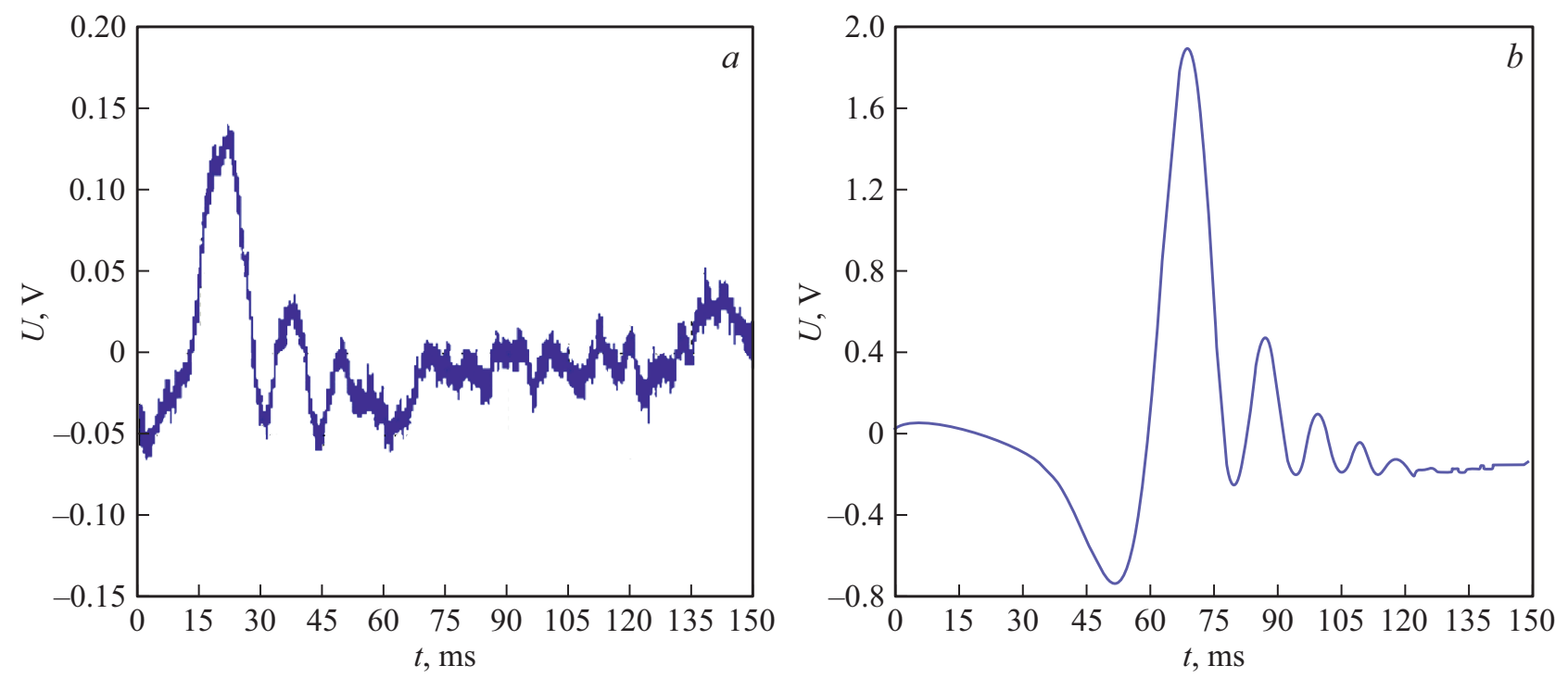

Рис. 2. Регистрируемый сигнал ЯМР от соляной кислоты при $T=18.3^{\circ} \mathrm{C}$ : без накопления $(a)$, на выходе схемы накопления $(b)$.

$92 \mathrm{~mm}$ и толщиной $8 \mathrm{~mm}$. От края диска по его диаметру были сделаны две полоски в виде ступенек с углублением к центру (ширина каждой ступеньки $3 \mathrm{~mm}$, высота $2 \mathrm{~mm})$. В результате этого внутри каждой из вставок 2 (рис. 1) образовалось свободное пространство по оси действия поля $B_{0}$ в виде впадин (цилиндрической формы, глубиной $4 \mathrm{~mm}$, диаметром $80 \mathrm{~mm}$ ), в них и были размещены каркасы с катушками модуляции. Поэтому расстояние $d_{z}$ между полюсами магнитов 1 увеличили только на $10 \mathrm{~mm}$ по сравнению с первоначальным $\left(d_{z}=16 \mathrm{~mm}\right)$ для размещения изготовленных вставок. Оно составило $d_{z}=26 \mathrm{~mm}$. В новой разработанной конструкции магнитной системы также была сохранена возможность механической юстировки взаимного расположения полюсных наконечников, применяемая ранее в работах $[4,6,8,15,17]$.

Как показали экспериментальные исследования после размещения изготовленных вставок (шиммов), на полюcax магнитов индукция $B_{0}$ в зоне размещения катушки регистрация увеличилась до $0.132 \mathrm{~T}$, а неоднородность 
Значения продольного $T_{1}$ и поперечного $T_{2}$ времен релаксации в растворе воды с хлоридом железа-3 при различных концентрациях между ними

\begin{tabular}{c|c|c}
\hline $\begin{array}{c}\text { Соотношение между концентрациями } \\
\text { воды и хлорида железа-3 в растворе }\end{array}$ & $T_{1}, \mathrm{~s}$ & $T_{2}, \mathrm{~ms}$ \\
\hline $80 \%$ к $20 \%$ & $2.343 \pm 0.021$ & $1.432 \pm 0.013$ \\
\hline $75 \%$ к $25 \%$ & $1.924 \pm 0.017$ & $1.323 \pm 0.012$ \\
\hline $66.66 \%$ к $33.33 \%$ & $1.483 \pm 0.013$ & $1.253 \pm 0.011$ \\
\hline $50 \%$ к $50 \%$ & $0.882 \pm 0.008$ & $1.161 \pm 0.010$
\end{tabular}

магнитного поля уменьшилась до $0.3 \cdot 10^{-4} \mathrm{~cm}^{-1}$. Использование вставок дало возможность увеличить $V_{R}$ более чем в 10 раз. Изменение значений $V_{R}$ и $B_{0}$ позволило увеличить более чем в 11 раз отношение $S / N$ регистрируемого сигнала ЯМР от исследуемых сред по сравнению с магнитной системой без вставок.

В новой конструкции малогабаритного ЯМР-спектрометра АПЧ $f_{\text {ad }}$ на резонанс реализована на микроконтроллере STM32 (ядро ARM Cortex M3 STM32F100RBT6B). Также на его базе были реализованы новые схемы автоподстройки уровня генерации (поля $H_{1}$ ) автодинного детектора, частоты $f_{m}$ и амплитуды $H_{m}$ поля модуляции $B_{0}$ по максимальному отношению $S / N$.

Для обеспечения измерения констант релаксации с погрешностью не выше $1.0 \%$ на базе микроконтроллера была реализована схема накопления сигнала ЯМР. В разработанной конструкции малогабаритного ЯМР-спектрометра после АПЧ на резонанс перед измерением $T_{1}$ и $T_{2}$ осуществлялось 32 накопления сигнала ЯМР. Этого было вполне достаточно для того, чтобы $S / N$ регистрируемого сигнала ЯМР от большинства ядер стал выше 3.0. Остальной резерв схемы накопления (более $10^{4}$ ) был предназначен для реализации возможности регистрации в исключительных случаях сигналов ЯМР от ядер с очень низкой чувствительностью (например, серы и т.д.). Необходимо отметить, что использование 32 накоплений незначительно увеличивает время измерения $t_{R}$ констант релаксации $T_{1}$ и $T_{2}$, например при $f_{m}=10 \mathrm{~Hz}-$ на $4 \mathrm{~s}$.

С использованием зарегистрированных сигналов ЯМР (рис. 2) и разработанных методик для измерения времен релаксации, представленных в работах $[4,6,18,19]$, были определены значения $T_{1}=1.27 \pm 0.01 \mathrm{~s} \quad$ и $T_{2}=33.2 \pm 0.03 \mathrm{~ms}$ для соляной кислоты.

В результате проведенных экспериментов было установлено, что для измерения времени поперечной релаксации $T_{2}$ по спаду огибающей регистрируемого сигнала ЯМР с погрешностью менее $1.0 \%$ необходимо также выполнение следующего соотношения:

$$
T_{m}>5 T_{2},
$$

где $T_{m}=1 / f_{m}-$ период модуляции поля $B_{0}$.
Полученное нами соотношение (3) является еще одной особенностью регистрации сигнала ЯМР в слабых магнитных полях.

Проведенные исследования конденсированных сред с различными константами релаксации при одинаковой температуре в лаборатории показали, что уменьшение частоты модуляции $f_{m}$ (чтобы обеспечить выполнение (3) в случае регистрации сигналов ЯМР от сред с большим $T_{2}$ ) приводит к уменьшению отношения $S / N$. Данное уменьшение до определенного момента можно компенсировать увеличением $H_{1}$ и $H_{m}$. Но так как размер катушек регистрации и модуляции ограничен по причине жестких требований к массо-габаритным характеристикам магнитной системы для сохранения мобильности малогабаритного ЯМР-спектрометра, то это приводит к ограничению возможностей по исследованию им конденсированных сред, что также является еще одной особенностью метода ЯМР в слабых полях.

\section{Результаты экспериментальных исследований и их обсуждение}

На рис. 3 в качестве примера представлены зарегистрированные сигналы ЯМР на резонансной частоте ядер хлора $f_{\mathrm{Cl}}$ в разработанной конструкции малогабаритного ЯМР-спектрометра от раствора воды с хлоридом железа-3 при различных концентрациях между ними.

Анализ полученных экспериментальных результатов показывает, что даже незначительное изменение концентрации ядер хлора при изменении соотношения между компонентами в растворе приводит к изменению амплитуды пиков („виглей“) в регистрируемом сигнале ЯМР и расстоянию между ними. Это означает, что система АПЧ-спектрометра произвела точную настройку частоты регистрации сигнала ЯМР на резонанс по ядрам хлора. Стоит также отметить, что ядра хлора обладают не самой высокой чувствительностью к методу ЯМР [15-17]. Но полученный результат позволяет сделать следующий вывод. Так как после 10 накоплений сигнала ЯМР отношение $S / N$ больше 25 (без накопления оно было бы меньше 8), то разработанный нами малогабаритный ЯМР-спектрометр можно использовать 

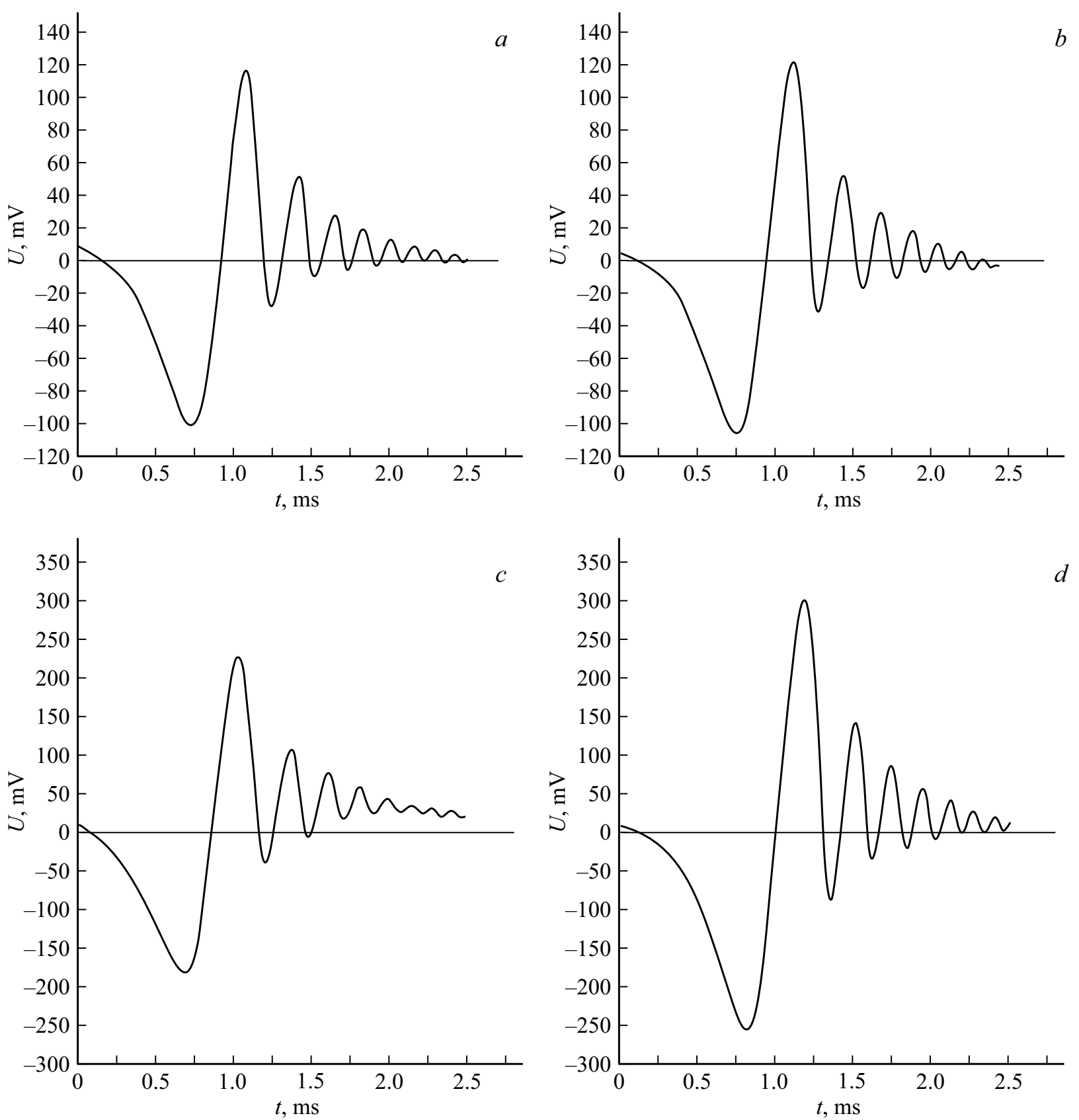

Рис. 3. Регистрируемый сигнал ЯМР при температуре $T=18.2^{\circ} \mathrm{C}$ от раствора воды с хлоридом железа-3 на выходе схемы накопления: соответствует смеси воды и хлорида железа-3 в пропорции (a) 80\% к 20\%, (b) 75\% к 25\%, (c) 66.66\% к 33.33\%, (d) $50 \%$ к $50 \%$.

для исследования сред по ядрам с чувствительностью, меньшей не более чем в 3 раза по сравнению с ядрами хлора (увеличение чувствительности, например, в два раза увеличивает отношение $S / N$ также в два раза при регистрации сигнала ЯМР). Устойчивая работа системы АПЧ fad на резонанс обеспечивается при $S / N>2.0$. С использованием разработанных методик для измерения времен релаксации, представленных в $[4,6,18,19]$, были определены значения $T_{1}$ и $T_{2}$ для этих растворов (таблица).
Регистрация спектра в новой разработанной нами конструкции малогабаритного ЯМР-спектрометра была реализована следующим образом. При постоянной величине индукции магнитного поля $B_{0}$ измеряется изменение амплитуды $U_{s}$ регистрируемого сигнала ЯМР от изменения частоты регистрации сигнала ЯМР $f_{\text {ad }}$ (автодинного детектора 10). Тем самым происходит регистрация спектра поглощения исследуемой среды от ядер, обладающих магнитными моментами, содержащимися в исследуемой среде. На рис. 4-6 в качестве 
примера представлена зависимость изменения амплитуды $U_{s}$ регистрируемого сигнала ЯМР от частоты $f_{\text {ad }}$ водного раствора гидроксида натрия, хлорида натрия и соляной кислоты при $B_{0}=0.132 \mathrm{~T}$.

По полученным на рис. 4,5 зависимостям $U_{s}$ от $f_{\text {ad }}$ (спектры поглощения) можно определить, какие ядра с магнитными моментами присутствуют в исследуемой среде и их относительные концентрации. Аналогичные зависимости для исследования различных сред регистрируются в стационарных, а также настольных импульсных ЯМР-спектрометрах высокого разрешения.

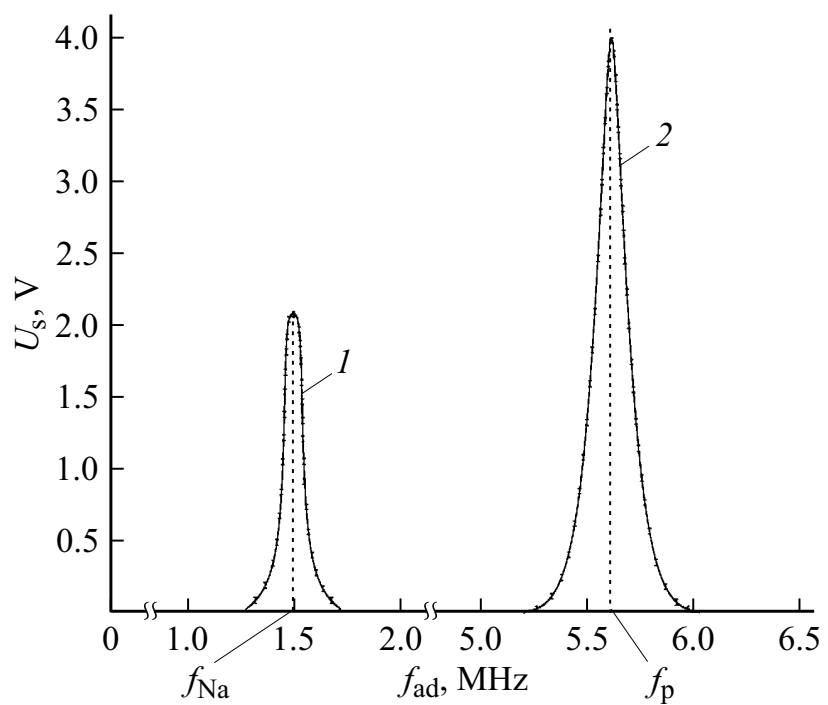

Pис. 4. Спектр поглощения водного раствора гидроксида натрия при температуре $T=20.3^{\circ} \mathrm{C}$. Кривая 1 соответствует регистрации сигнала ЯМР в зоне расстройки частоты автодинного детектора $f_{\text {ad }}$ от резонансной частоты ядер натрия $f_{\mathrm{Na}}$, кривая $2-$ протонов $f_{\mathrm{p}}$.

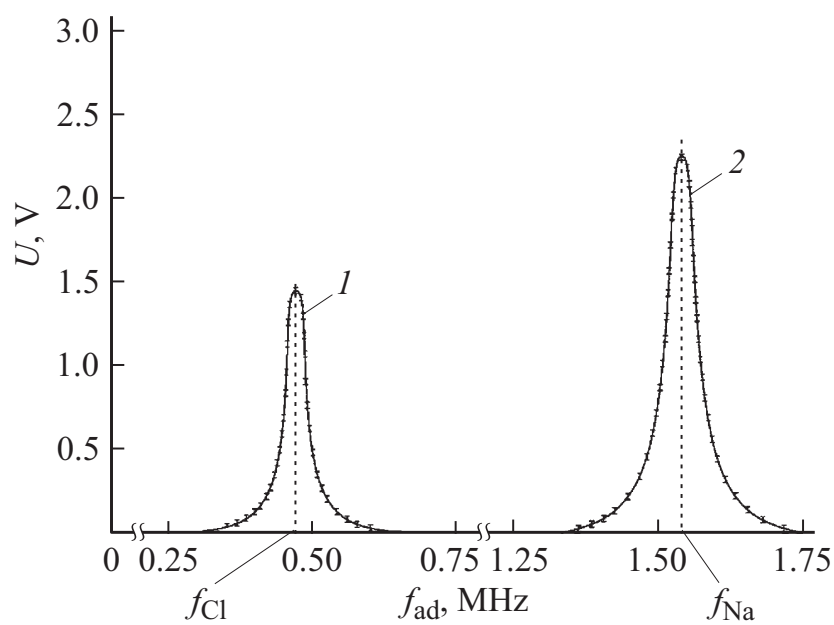

Рис. 5. Спектр поглощения хлорида натрия при температуре $T=20.4^{\circ} \mathrm{C}$. Кривая 1 соответствует регистрации сигнала ЯМР в зоне расстройки частоты автодинного детектора $f_{\text {ad }}$ от резонансной частоты ядер хлора $f_{\mathrm{Cl}}$, кривая $2-$ натрия $f_{\mathrm{Na}}$.

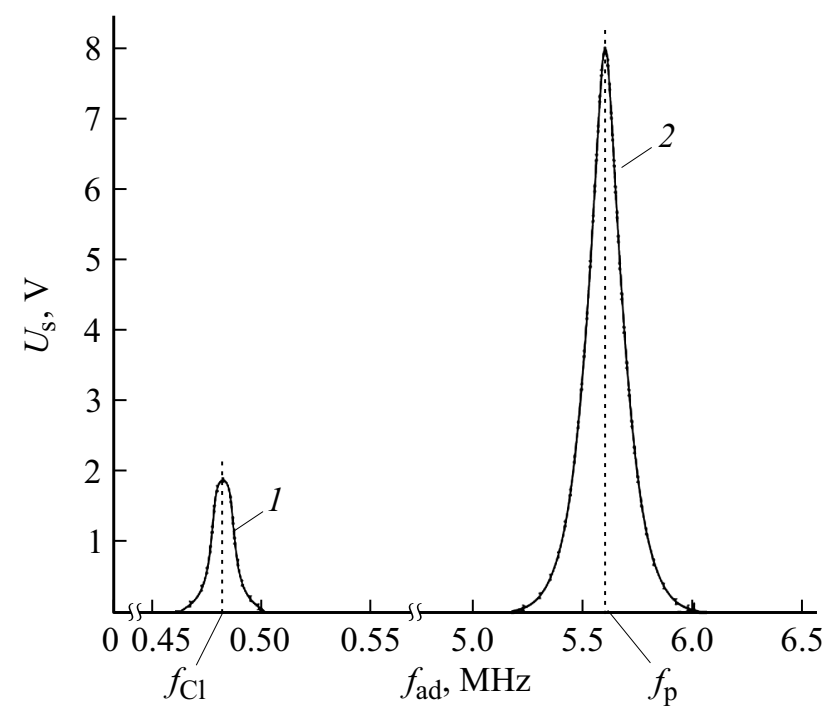

Рис. 6. Спектр поглощения водного раствора соляной кислоты при температуре $T=20.2^{\circ} \mathrm{C}$. Кривая 1 соответствует регистрации сигнала ЯМР в зоне расстройки частоты автодинного детектора $f_{\text {ad }}$ от резонансной частоты ядер натрия $f_{\mathrm{Cl}}$, кривая $2-$ протонов $f_{\mathrm{p}}$.

\section{Заключение}

Полученные экспериментальные результаты показали, что разработанный с учетом установленных нами особенностей регистрации сигнала ЯМР в слабых полях малогабаритный ЯМР-спектрометр позволяет регистрировать спектры ЯМР, что существенно расширяет возможности экспресс-контроля состояния конденсированных сред по сравнению с ранее разработанными приборами $[4,6,8]$.

Впервые была реализована возможность широкой перестройки частоты $f_{\text {ad }}$ с АПЧ на резонанс для регистрации спектров ЯМР в слабом поле, которая позволила определять наличие различных ядер в исследуемой среде и их относительные концентрации.

В исключительных случаях разработанным малогабаритным ЯМР-спектрометром в условиях лаборатории возможно реализовать регистрацию сигналов ЯМР от ядер углерода и серы с использованием большого числа накоплений (например, $10^{4}$ и более) при работе системы АПЧ. Отметим, что при исследовании сред в промышленных ЯМР-спектрометрах наиболее востребованная информация - это информация, получаемая при регистрации сигнала от ядер углерода-13 $\left({ }^{13} \mathrm{C}\right)[3,5,8,12]$. Однако значительное число накоплений при работе системы АПЧ создает большие трудности в использовании данного прибора в полевых условиях.

\section{Конфликт интересов}

Авторы заявляют, что у них нет конфликта интересов. 


\section{Список литературы}

[1] Дудкин В.И., Пахомов Л.Н. Квантовая электроника. СПб.: Издательство Политехнического университета, 2012. $496 \mathrm{c}$.

[2] Камаев Р.С., Газизов Э.Г. // ЖПС. 2010. Т. 77. № 3. С. 347.

[3] Filippov A.V., Rudakova M.A., Skirda V.D. // Magnetic Resonance in Chemistry. 2012. V. 50. N 2. P. 114.

[4] Karseev A.Yu., Vologdin V.A., Davydov V.V. // J. Physics: Conference Series. 2015. V. 643(1). P. 012108.

[5] Бричков А.С., Козик В.В. // Известия вузов. Физика. 2014. T. 57. № 7-2. C. 26.

[6] Давыдов В.В., Дудкин В.И., Карсеев А.Ю. // ПТЭ. 2015. № 2. C. 72.

[7] Толсторожсев Г.Б., Бельков М.В., Райченок Т.Ф., Скорняков И.В., Шадыро О.И., Бринкевич С.Д., Самович С.Н., Базыль О.К., Артюхов В.В., Майер Г.В. // Опт. и спектр. 2013. T. 115. № 5. С. 807.

[8] Давыдов В.В., Дудкин В.И., Карсеев А.Ю. // Измерительная техника. 2014. № 8. С. 44.

[9] Вольфганг Д. Современная лазерная спектроскопия. М.: Издательство Интеллект, 2014. 1072 с.

[10] Panchenko P.A., Fedorov Y.V., Perevalov V.P., Jonusauskas G., Fedorova O.A. // J. Phys. Chem. A. 2010. V. 114. N 12. P. 4118.

[11] Николаева М.В., Пузык М.В. // Опт. и спектр. 2014. Т. 116. № 2. C. 227.

[12] Erdogru Y., Manimaran D., Gulluolu M.T., Amalanathan M., Hubert Joe I., Yurdakul N. // Опт. и спектр. 2013. Т. 113. № 4. C. 573.

[13] Порхун В.И. // Известия вузов. Приборостроение. 2010. T. 53. № 10. С. 65.

[14] Ахадов Я.Ю. Диэлектрические параметры чистых сред. М.: Издательство МАИ, 1999. 856 с.

[15] Давыдов В.В., Дудкин В.И., Карсеев А.Ю. // ПТЭ. 2015. № 6. C. 84 .

[16] Абрагам А. Ядерный магнетизм. М.: Иностранная лит-ра, 1963. $612 \mathrm{c}$

[17] Леше А. Ядерная индукция. М.: Иностранная лит-ра, 1963. $684 \mathrm{c}$.

[18] Давыдов В.В. // Опт. и спектр. 2016. Т. 121. № 1. С. 18.

[19] Davydov V.V., Cheremiskina A.V., Velichko E.N., Karseev A.Yu. // J. Physics: Conference Series. 2014. V. 541(1). P. 012006 